\title{
I4.2 Causes of early death in juvenile onset systemic lupus erythematosus (JSLE)
}

B Bader-Meunier*1, A Klein 2, A Aggarwal ${ }^{3}$, R Merino ${ }^{4}$, R Russo ${ }^{5}$, F Sztajnbok ${ }^{6}$, T Avcin 7 , S Knupp ${ }^{11}$, R Khubchandani ${ }^{9}$, S Ozen ${ }^{8}$, R Cimaz ${ }^{10}$ and P Quartier ${ }^{1}$

\begin{abstract}
Address: ${ }^{1}$ Necker Hospital, Paris, France, ${ }^{2}$ Saint Jacques Hospital, Besançon, France, ${ }^{3}$ SGPGI, Lucknow, India, ${ }^{4}$ La Paz Hospital, Madrid, Spain, ${ }^{5}$ Garrahan Hospital, Buenos Aires, Argentina, ${ }^{6}$ Universitade do Estato do Rio de Janeiro, Rio de Janeireo, Brazil, 7 University children's hospital, Ljubljana, Slovenia, ${ }^{8}$ Hacettepe university, Ankara, Turkey, 'Jasklov Hospital, Mumbai, India, ${ }^{10}$ Hospices civils de Lyon, Lyon, France and ${ }^{11}$ IPPMG, Rio Do Janeiro, Brazil

* Corresponding author
\end{abstract}

from I5th Paediatric Rheumatology European Society (PreS) Congress

London, UK. 14-17 September 2008

Published: 15 September 2008

Pediatric Rheumatology 2008, 6(Suppl I):S29 doi:10.1 186/1546-0096-6-SI-S29

This abstract is available from: http://www.ped-rheum.com/content/6/SI/S29

(c) 2008 Bader-Meunier et al; licensee BioMed Central Ltd.

\section{Purpose}

To describe the causes of death occurring within the first month following the diagnosis of JSLE in order to prevent them.

\section{Methods}

Retrospective study of causes of early death in JSLE patients during the period 1995 - 2006 conducted on behalf of Paediatric Rheumatology International Trials Organization (PRINTO). All the patients fulfilled the American College of Rheumatology (ACR) criteria for the diagnosis of SLE, and were diagnosed before 16 years of age.

\section{Results}

Death was recorded in 5 girls and 1 boy including three non Caucasian patients, aged 6 to 16 years. Initial SLE manifestations comprised at least three organ involvement, including at least two major organ involvement: central nervous system (4 patients), kidney (5 patients), pancreas ( 2 patients), hematopoietic system (3 patients), heart ( 1 patient), skin ( 2 patients), and joints ( 3 patients). Despite administration of oral and pulsed steroids, associated twice with intravenous cyclophosphamide, SLE activity remained uncontrolled in all the patients. Death resulted from SLE organ failure either alone in 2 patients (pancreatitis: 1 patient, neurolupus: 1 patient), either associated with thrombotic event (catastrophic antiphos- pholipid syndrome: 2 patients, pulmonary thromboembolism: 1 patient with nephrotic syndrome) and/or infection (paravertebral abcess: 1 patient, pneumococcal sepsis: 1 patient).

\section{Conclusion}

Despite prompt diagnosis and management, death may occur at presentation of juvenile-onset SLE. Half of them resulted from thromboembolic event in patients with nephrotic syndrome or APL. These features suggest that prompt prophylactic anticoagulation may be beneficial in patients with severe SLE multiorgan involvements associated with risk factors of thromboembolic event. 